\title{
Essential medicines containing ethanol elevate blood acetaldehyde concentrations in neonates
}

\author{
H. C. Pandya ${ }^{1}$ (1) - H. Mulla ${ }^{2} \cdot$ M. Hubbard ${ }^{3}$ - R. L. Cordell ${ }^{4}$ P. S. Monks ${ }^{4} \cdot$ S. Yakkundi ${ }^{5}$. \\ J. C. McElnay ${ }^{5}$ - A. J. Nunn ${ }^{6}$ - M. A. Turner ${ }^{7}$ o on behalf of the ESNEE consortium
}

Received: 9 November 2015 /Revised: 3 March 2016/Accepted: 8 March 2016/Published online: 21 March 2016

(C) The Author(s) 2016. This article is published with open access at Springerlink.com

\begin{abstract}
Neonates administered ethanol-containing medicines are potentially at risk of dose-dependent injury through exposure to ethanol and its metabolite, acetaldehyde. Here, we determine blood ethanol and acetaldehyde concentrations in 49 preterm infants (median birth weight $=1190 \mathrm{~g}$ ) dosed with iron or furosemide, medicines that contain different amounts of ethanol, and in 11 control group infants (median birth weight $=1920 \mathrm{~g}$ ) who were not on any medications. Median ethanol concentrations in neonates administered iron or furosemide were 0.33 $($ range $=0-4.92) \mathrm{mg} / \mathrm{L}, 0.39($ range $=0-72.77) \mathrm{mg} / \mathrm{L}$ and
\end{abstract}

Communicated by Patrick Van Reempts in control group infants were 0.15 (range $=0.03-5.4) \mathrm{mg}$ / L. Median acetaldehyde concentrations in neonates administered iron or furosemide were 0.16 (range $=0-8.89) \mathrm{mg} /$ $\mathrm{L}, 0.21$ (range $=0-2.43) \mathrm{mg} / \mathrm{L}$ and in control group infants were 0.01 (range $=0-0.14) \mathrm{mg} / \mathrm{L}$. There was no discernible relationship between blood ethanol or acetaldehyde concentrations and time after medication dose.

Conclusion: Although infants dosed with iron or furosemide had low blood ethanol concentrations, blood acetaldehyde concentrations were consistent with moderate alcohol exposure. The data suggest the need to account for the effects
H. C. Pandya

hp28@le.ac.uk

H. Mulla

hussain.mulla@uhl-tr.nhs.uk

M. Hubbard

marie.hubbard@uhl-tr.nhs.uk

R. L. Cordell

rc145@le.ac.uk

P. S. Monks

psm7@le.ac.uk

S. Yakkundi

s.yakkundi@qub.ac.uk

J. C. McElnay

s.yakkundi@qub.ac.uk

A. J. Nunn

tnunn100@hotmail.com
M. A. Turner

Mark.Turner@liverpool.ac.uk

on behalf of the ESNEE consortium

1 Department of Infection, Immunity and Inflammation, University of Leicester, University Road, Leicester LE1 9HN, UK

2 Department of Pharmacy, University of Hospitals Leicester NHS Trust, Leicester, UK

3 Neonatal Unit University of Hospitals Leicester NHS Trust, Leicester, UK

4 Department of Chemistry, University of Leicester, Leicester, UK

5 Department of Pharmacy, Queen's University Belfast, Belfast, UK

6 Alder Hey Children's NHS Foundation Trust, Liverpool, UK

7 Department of Women's and Children's Health, Institute of Translational Medicine, University of Liverpool, Liverpool, UK 
of acetaldehyde in the benefit-risk analysis of administering ethanol-containing medicines to neonates.

\section{What is Known:}

- Neonates are commonly treated with ethanol-containing medicines, such as iron and furosemide.

- However, there is no data on whether this leads to appreciable increases in blood concentrations of ethanol or its metabolite, acetaldehyde.

What is New:

- In this study, we find low blood ethanol concentrations in neonates administered iron and/or furosemide but markedly elevated blood acetaldehyde concentrations in some infants receiving these medicines.

- Our data suggest that ethanol in drugs may cause elevation of blood acetaldehyde, a potentially toxic metabolite.

Keyword Infants $\cdot$ Drug excipients $\cdot$ Alcohol

$\begin{array}{ll}\text { Abbreviations } \\ \text { ALDH } & \begin{array}{l}\text { Aldehyde dehydrogenase } \\ \text { CRF }\end{array} \\ \text { Case report form } \\ \text { ESNEE } & \begin{array}{l}\text { European Study of Neonatal Exposure } \\ \text { to Excipients }\end{array} \\ \text { GC-MS } & \begin{array}{l}\text { Gas chromatography coupled mass } \\ \text { spectrometry }\end{array}\end{array}$

\section{Introduction}

Preterm neonates are often chronically treated with oral liquid formulation medicines that contain ethanol as an excipient $[12,13,20,22]$. In this context, ethanol is used as an organic phase co-solvent. It also has antimicrobial preservative properties [12, 13, 20,22]. Whittaker et al. have previously ethanol exposure in preterm neonates treated with oral liquid drugs, in particular furosemide and iron [2], and raised concerns that a chronic drug therapy could cause an acute and/or chronic ethanol toxicity $[12,22]$.

There is little data on the effects of ethanol exposure in preterm infants. In infants and children, ethanol poisoning may cause hypoglycaemia, cardio-respiratory depression and seizures [16]. Exposure to ethanol in utero is associated with fetal alcohol syndrome [2]. The pathophysiology of fetal alcohol syndrome is complex. It involves exposure of tissues to ethanol and acetaldehyde, a highly reactive and toxic byproduct of ethanol metabolism during vulnerable periods of organ development [2]. Since pre- and post- natal organ development correlates with age, it follows that neonates born prematurely and exposed to ethanol could be at risk of 'ex utero fetal alcohol syndrome'. Moreover, as ethanol effects in adults correlate with blood ethanol concentrations [24], it is likely that adverse effects of ethanol in preterm infants will also correlate with blood ethanol concentrations.
In the UK, oral liquid iron and furosemide medicines contain $0.3(300 \mathrm{mg} / 100 \mathrm{ml})$ and $7.5 \%(7500 \mathrm{mg} / 100 \mathrm{ml})$ ethanol, respectively. In our neonatal unit, if clinically indicated, preterm infants receive between 1 and $2.5 \mathrm{ml}$ of iron solution preparation daily (ethanol 3-7.5 mg) and up to $1 \mathrm{ml} / \mathrm{kg}$ furosemide daily (ethanol $75 \mathrm{mg} / \mathrm{kg}$ ). To test the hypothesis that administration of these drug medicines to preterm neonates elevates blood ethanol concentrations, we conducted a population study of blood ethanol and acetaldehyde concentrations in infants treated with oral iron and furosemide.

\section{Methods}

Seventy-six babies receiving iron and/or furosemide preparations and 11 control subjects were enrolled into this study. The study received ethical approval from NRES Committee North West - Greater Manchester North Rec, ref no: 11/NW/0665. The investigation was conducted in line with the Declaration of Helsinki. All children were recruited from the neonatal units within University Hospitals of Leicester NHS Trust. Infants on oral iron and/or furosemide therapy were eligible as were infants who were on no ethanol-containing medicines (control group). Neonates were excluded if parents or guardians refused or were unable to give valid consent. Neonates were prescribed iron or furosemide based on clinical indications and according to unit protocols. Control babies were not on any medication containing ethanol. All oral medicines were administered with feeds (milk) and given via a naso/ orogastric tube or mixed into a bottle with milk. Demographic and clinical details including birth weight, gestation, drugs doses and drug dose times were recorded on a case report form (CRF).

\section{Sample collection and analysis}

Ethanol and acetaldehyde were measured in blood samples using a static headspace gas chromatography coupled mass spectrometry (GC-MS) as previously described by our group [5]. The technique allows quantification of ethanol and acetaldehyde in micro-volumes of blood using n-propanol as an internal standard. The linearity of the method was established over the range $0.1-100 \mathrm{mg} / \mathrm{L}\left(R^{2}>0.99\right)$ : limit of detection $=0.1 \mathrm{mg} / \mathrm{L}$, lower limit of quantification $=0.5 \mathrm{mg} /$ L [5]. Intra- and inter-day precision and accuracy for ethanol and acetaldehyde were 20 and $\leq 25 \%$, respectively. Most babies receiving iron and/or furosemide had blood ethanol concentrations measured on more than one occasion. The median number of samples obtained from study babies was 4 (range 1-22). Seven babies in the control group had blood ethanol concentrations measured on one occasion only. The timing of blood samples in relation to administration of iron or furosemide was entirely based on the clinical needs of the 
child since study blood was opportunistically scavenged from samples taken for routine blood tests.

\section{Data analysis}

Data from each CRF, comprising the iron and furosemide dosing pattern and blood-sampling times were reconciled with blood ethanol and acetaldehyde concentrations. The data were collated and analysed using Excel and GraphPadPrism software. Ethanol and acetaldehyde concentrations were related to either iron or furosemide administration based on the medicine the child received prior to the blood sample. Differences in blood ethanol and acetaldehyde concentrations between groups were compared using an unpaired Student's $t$ test. Linear correlation analysis was performed using Pearson product moment correlation coefficient.

\section{Results}

\section{Patient demographics}

Seventy-six babies receiving iron and/or furosemide and 11 babies receiving neither (control group) were recruited into the study. Forty-nine infants receiving iron and/or furosemide and 11 babies in control provided at least 1 blood sample for analysis. Demographic and clinical data of babies providing 1 or more blood samples are presented in Tables 1 and 2. In comparison to infants receiving iron and/or furosemide, control group babies were significantly heavier (median birth weight 1.92 vs. $1.19 \mathrm{~kg}$ ) and older at birth (median gestational age at birth 231 vs. 193 days) and had significantly greater post-menstrual weight (median weight $2.05 \mathrm{vs} .1 .87 \mathrm{~kg}$ ) at recruitment. No baby in either group had clinical or biochemical evidence of hepatic or renal dysfunction.

\section{Blood ethanol and acetaldehyde concentrations in neonates receiving iron and/or furosemide}

Blood ethanol and acetaldehyde concentrations were measured in 348 blood samples from babies receiving either iron only ( $N=35$ babies), iron and furosemide ( $N=10$ babies) or furosemide only ( $N=4$ babies). Ethanol concentrations above $1 \mathrm{mg} / \mathrm{L}$ were found in 67 blood samples (20\% of total) from 26 infants; 2 babies ( 2 blood samples) had blood ethanol concentrations above $20 \mathrm{mg} / \mathrm{L}$. Median ethanol concentrations in the iron ( $N=231$ blood samples) and the furosemide $(N=117$ blood samples) groups were 0.33 (range $=0-4.92$ ) and 0.39 (range $=0-72.8) \mathrm{mg} / \mathrm{L}$, respectively. There was no discernible relationship between blood ethanol concentrations and time after dose of an ethanol-containing drug medicine (Fig. 1). However, sub-analysis showed that infants with ethanol $>5 \mathrm{mg} / \mathrm{L}$ received an ethanol-containing medicine within $24 \mathrm{~h}$ of obtaining the blood sample. In control group infants ( $N=14$ time points), ethanol concentrations ranged between $0.03-5.4 \mathrm{mg} / \mathrm{L}$ (median $=0.15 \mathrm{mg} / \mathrm{L})$. Three blood samples from 3 infants ( $28 \%$ of total) in this group had ethanol concentrations above $1 \mathrm{mg} / \mathrm{L}$. There was no significant difference in blood ethanol concentrations in infants receiving ethanolcontaining medicines and control group infants $(P>0.05)$.
Table 1 Demographics, liver and renal function tests of neonates recruited into the study and providing blood samples. Results are from analysis of serum

\begin{tabular}{lll}
\hline & $\begin{array}{l}\text { Iron and/or furosemide neonates } \\
\text { median (range) } N=49\end{array}$ & $\begin{array}{l}\text { Control group neonates } \\
\text { median (range) } \\
N=11\end{array}$ \\
\hline Birth weight & $1.19(0.63-2.38)$ & $1.92(0.61-3.93)$ \\
Gestational age at birth (days) & $193(171-245)$ & $231(171-289)$ \\
APGAR score & $8(4-10)$ & $8(4-10)$ \\
Weight at recruitment (kg) & $1.87(1.06-3.34)$ & $2.05(0.52-3.93)$ \\
Post-menstrual age at recruitment (days) & $247(190-326)$ & $239(174-293)$ \\
Post-natal age at recruitment (days) & $29(10-94)$ & $10(2-27)$ \\
Sampling times after last dose (hours) & $30.8(0-321.6)$ & Not applicable \\
Dose of ethanol (mg)/dose of iron or furosemide & $7.24(2.27-78.42)$ & Nil \\
Duration in study (days) & $28(0-101)$ & $1.5(1-5)$ \\
Albumin (g/dl) & $44(18-44)$ & $34(20-62)$ \\
Alkaline phosphatase (IU/L) & $442(124-1312)$ & $313(27-532)$ \\
Alanine transaminase (IU/L, ALT) & $18(10-120)$ & $5(0.4-10)$ \\
Bilirubin (umol/L) & $32(2-118)$ & Not determined \\
Creatinine (umol/L) & $30(19-135)$ & $49(20-63)$ \\
Urea (mmol/L) & $4.2(0.4-11.8)$ & $3.9(1.2-6.9)$ \\
\hline
\end{tabular}


Table 2 Demographics of neonates grouped according to ethanol-containing medicine

\begin{tabular}{llll}
\hline & $\begin{array}{l}\text { Iron only neonates } \\
\text { (median and range) }\end{array}$ & $\begin{array}{l}\text { Iron and furosemide } \\
\text { (median and range) }\end{array}$ & $\begin{array}{l}\text { Furosemide only } \\
\text { (median and range) }\end{array}$ \\
\hline Gestational age at birth (days) & $200(175-245)$ & $192(171-227)$ & $200(185-209)$ \\
Post-natal age at recruitment (days) & $30(10-82)$ & $27(12-52)$ & $28.5(22-94)$ \\
Weight at recruitment $(\mathrm{kg})$ & $2.04(1.06-3.34)$ & $1.68(1.04-3.28)$ & $1.58(1.15-3.09)$ \\
Ethanol dose/dose of medicine (mg/kg) & $1.1(0.7-3.9)$ & $6.7(1.4-10.9)$ & $11.8(9.1-14.5)$ \\
\hline
\end{tabular}

Two hundred seventeen blood samples from 42 infants administered iron and/or furosemide blood acetaldehyde concentrations were above $0.1 \mathrm{mg} / \mathrm{L}$. Fifteen babies ( $N=117$ blood samples) had acetaldehyde concentrations above $0.5 \mathrm{mg} / \mathrm{L}$. Median blood acetaldehyde concentrations in the iron $(N=231$ samples $)$ and the furosemide $(N=117$ samples) groups were 0.16 (range $=0-8.89)$ and 0.21 (range $=0-2.43) \mathrm{mg} / \mathrm{L}$, respectively. There was no discernible relationship between blood acetaldehyde concentration and time after dose of iron or furosemide (Fig. 1). In control group infants ( $N=14$ blood samples), the median blood acetaldehyde concentrations was 0.01 (range $=0-0.14) \mathrm{mg} / \mathrm{L}$. Two infants from this group had acetaldehyde concentrations above $0.1 \mathrm{mg} / \mathrm{L}$. Infants who received furosemide prior to blood sampling had significantly higher blood acetaldehyde concentrations than control group infants $(P=0.02)$. There was no significant difference in acetaldehyde concentrations comparing infants administered iron prior to blood sampling and control group infants $(P>0.05)$

\section{Correlation between blood ethanol and acetaldehyde concentrations}

There was a weak linear correlation between blood ethanol and blood acetaldehyde concentrations in infants who received iron and in infants who received furosemide before blood sampling (see Fig. 2), Pearson product moment coefficient, $R^{2}=0.05$ and $R^{2}=0.34$ for iron and furosemide, respectively, $P<0.01$ for both. There was a no significant linear correlation between blood ethanol and blood acetaldehyde in control group infants.

\section{Discussion}

This study shows that preterm babies administered iron and/or furosemide preparations formulated with ethanol have a broad range of blood ethanol and acetaldehyde concentrations. Relative to blood ethanol concentrations used to define drink-driving offences in many countries $(>500 \mathrm{mg} / \mathrm{L}$
Fig. 1 Blood concentrations of ethanol (a,c) and acetaldehyde $(\mathbf{b}, \mathbf{d})$ plotted against time. Blood concentrations are related to dosing with iron $(\mathbf{a}, \mathbf{b})$ or furosemide $(\mathbf{c}, \mathbf{d})$ according to the medication the child received prior to blood sampling. There is no discernible correlation between blood ethanol (white circle and black circle) or blood acetaldehyde (white triangle and black triangle) concentrations and time after administration of iron or furosemide
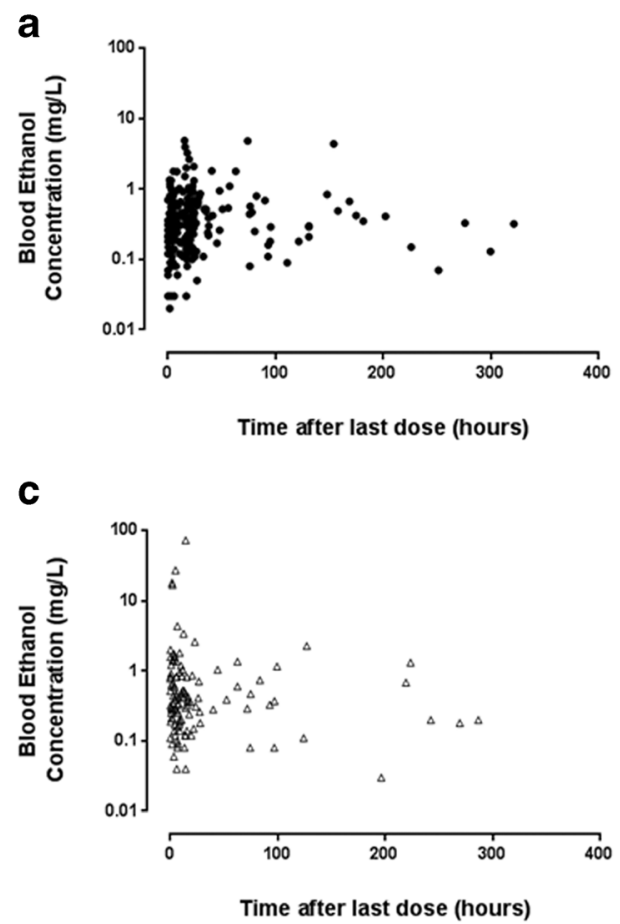

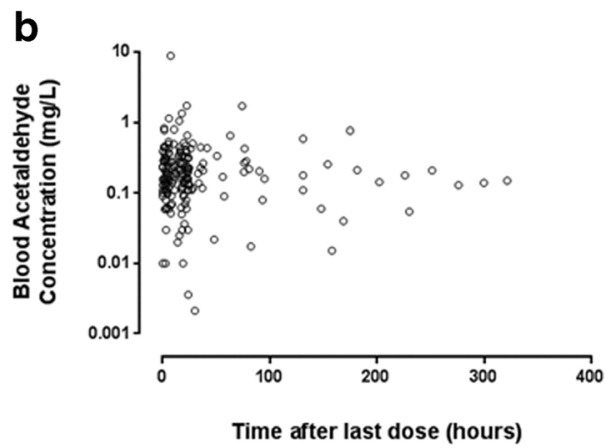

d

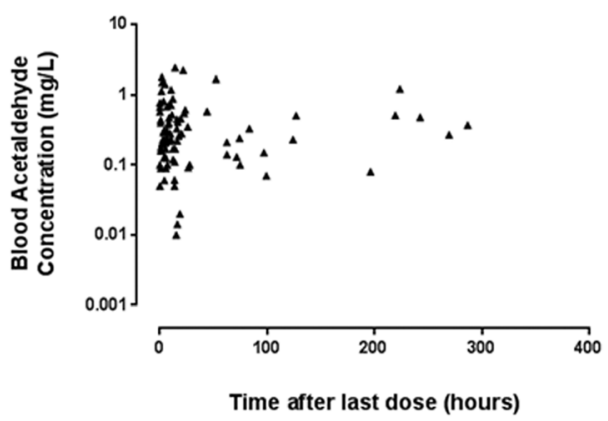




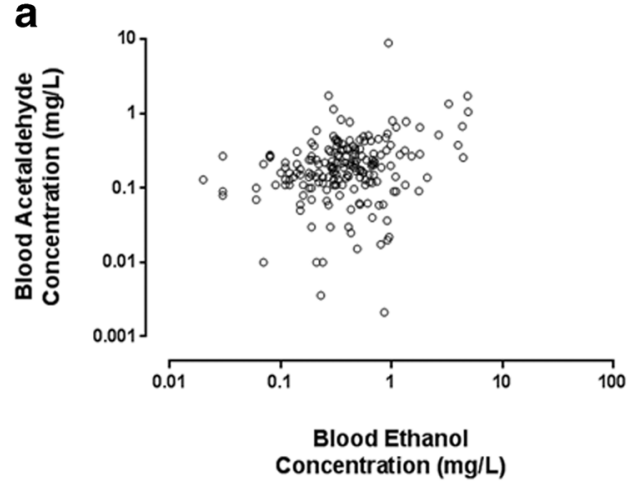

Fig. 2 Plots of blood ethanol vs. blood acetaldehyde concentrations in neonates receiving iron and/or furosemide. Blood concentrations are related to dosing with iron (a) or furosemide (b) according to the medication the child received prior to blood sampling. For both iron and

mainland Europe; $>800 \mathrm{mg} / \mathrm{L}$ UK and USA), blood ethanol concentrations in preterm infants were low. However, blood acetaldehyde concentrations in this population were higher than baseline concentrations $(<0.1 \mathrm{mg} / \mathrm{L})$ recorded in otherwise healthy, alcohol abstinent, adults.

There is little data on baseline blood ethanol concentration in ethanol-abstinent preterm neonates or young children. In healthy alcohol-abstaining adults, Sprung et al. found mean blood ethanol concentration of $0.27 \mathrm{mg} / \mathrm{L}$ with a range between $0.2-0.8 \mathrm{mg} / \mathrm{L}$ [18]. Although blood concentrations greater than $0.8 \mathrm{mg} / \mathrm{L}$ have been recorded in teenagers, mean ethanol concentrations (approximately $0.3 \mathrm{mg} / \mathrm{L}$ ) in this age group are not different to those recorded in adults $[9,14,18]$. The median and range of blood ethanol concentrations in infants receiving iron/furosemide are higher and broader than those determined in teenagers or adults in earlier studies. Over $50 \%$ of ethanol-exposed infants had at least 1 blood concentration greater than $1 \mathrm{mg} / \mathrm{L}$, and 1 neonate had a blood concentration of nearly $80 \mathrm{mg} / \mathrm{L}$. Despite these differences, our overall conclusion is that treatment of preterm infants with medicines containing between $0.3-7.5 \%(300-7500 \mathrm{mg} / 100 \mathrm{ml})$ ethanol does not result in toxicologically relevant systemic concentrations of ethanol in blood. Although fewer control group infants were found to have blood ethanol greater than $1 \mathrm{mg} / \mathrm{L}$ than those receiving iron and/or furosemide (28 vs. $53 \%$, respectively), median blood concentrations in these two groups were not significantly different.

The ethanol concentrations found in this study lend support to the concept that neonates have minimal systemic exposure to ethanol following enteral administration of ethanol-containing medicines at the presently reported dosing levels. This observation allays concerns raised in our previous study in which ethanol exposure was extrapolated from medicines, including iron and furosemide, routinely administered on a neonatal unit [22]. The most likely

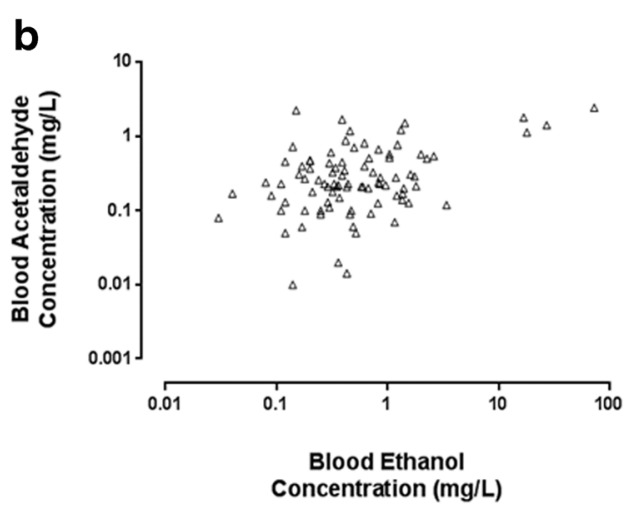

furosemide groups, there was a weak but significant correlation between blood ethanol and blood acetaldehyde concentrations. Pearson product moment coefficient, $R^{2}=0.05$ and $R^{2}=0.34$ for iron and furosemide groups, respectively, $P<0.01$ for both

explanation is efficient and rapid first-pass metabolism of ethanol to acetaldehyde.

Blood acetaldehyde concentrations in infants administered iron and/or furosemide were higher than those in control group infants. The implication of elevated blood acetaldehyde concentrations in infants receiving ethanol-containing medicines are unclear as little is known about the sources, kinetics and effects of acetaldehyde in this age group or even older children. In healthy adults, blood acetaldehyde concentrations correlate with dose of ethanol and aldehyde dehydrogenase (ALDH) genotype $[1,6]$. Whilst we did not genotype any of the infants recruited in this study, blood acetaldehyde concentrations did correlate with blood ethanol concentrations in neonates receiving iron and/or furosemide (Fig. 2) but not in control group infants (data not shown). These observations support an 'ethanol dose' effect on blood acetaldehyde concentrations in preterm infants. However, despite differences in administered doses of ethanol (see Table 2), there was no difference in acetaldehyde concentrations between the iron and furosemide groups. Since no infant was co-administered an acetaldehyde dehydrogenase inhibitor (e.g., metronidazole), one explanation is that measured acetaldehyde levels reflect cumulative doses of ethanol, which may not have been significantly different between the iron and furosemide groups. Ontogenic differences in acetaldehyde-metabolising capacity could also account for the lack of dose-effect. Nonetheless, our data suggest that the acetaldehyde to acetate conversion pathway becomes overwhelmed at relatively low doses of ethanol.

Presently, it is only possible to speculate about the clinical effects of elevated blood acetaldehyde concentrations in preterm babies. In adults, signs and symptoms of elevated blood acetaldehyde concentrations resemble those of ethanol intoxication. In 'aldehyde syndrome' of adults, elevated blood acetaldehyde due to ethanol ingestion is associated with facial flushing, tachycardia, reduced 
psychomotor function, muscle weakness and sleeplessness [9] These symptoms occur at blood acetaldehyde concentrations ranging between 0.4 and $2.6 \mathrm{mg} / \mathrm{L}[1,6,9]$. Thus, some of the infants in the present study had acetaldehyde concentrations consistent with symptoms associated with the aldehyde syndrome.

The relatively large numbers of patients recruited into this study can be mostly attributed to parents finding opportunistic collection and use of scavenged blood acceptable, as others have reported $[3,4,8]$. Whilst acceptable to parents, opportunistic sampling confers limitations on data analysis and interpretation. For example, if sampling time points do not cover the whole dosing period, it may not be possible to describe or model drug/excipient absorption and metabolism accurately.

As blood samples were processed and managed in clinical chemistry laboratories prior to being frozen for study assays, there is a possibility that some ethanol and acetaldehyde, both volatile at room temperature, could have evaporated from blood during processing of samples. Hence, if anything, the data presented may underestimate blood ethanol and acetaldehyde concentrations in babies recruited into the study. However, in-house in vitro studies indicate that recovery of ethanol and acetaldehyde from blood samples allowed to equilibrate with room air for $60 \mathrm{~min}$ was $>95 \%$ [5]. The small numbers of babies in the control group and demographic difference between control group infants and those receiving iron/furosemide are noteworthy, and we cannot exclude the possibility that these babies inadvertently ingested ethanol as some infants were fed with breast milk.

High blood acetaldehyde concentrations associated with administration of oral liquid iron and/or furosemide suggest that preterm neonates receiving these medicines are at risk of excipient-related neurotoxicity [6, 24]. However, there is insufficient data to quantify the impact of treatment with these medicines in this patient population. In the UK, oral liquid furosemide is generally administered to a small group of infants with heart failure or chronic lung disease of prematurity $[17,19]$. Neurocognitive outcomes in these two patient groups are recognised to be poor [11, 21]. In contrast, oral liquid iron is widely used to prevent and treat anaemia in neonates [10]. Hence, many more infants are likely to be exposed to ethanol through iron therapy than furosemide administration. Both iron and furosemide are listed as essential medicines by the World Health Organisation [10]. How our observations relating to use of oral liquid iron and furosemide in the UK extrapolate to other countries, other drugs and to older infants is unclear as drug prescribing and drug formulation practices vary considerably across the world [23]. The risks of medicines formulated with potentially toxic excipients such as ethanol are recognised hurdles to improving health outcomes for children globally $[7,15,23]$. In this context, our findings reinforce the global need to develop drugs and drug delivery systems suited to the needs of children [23].

Conclusion: This is the first study to determine blood concentrations of ethanol and its metabolite acetaldehyde in neonates receiving ethanol-containing medicines as part of routine care. Neonates were found to have low blood ethanol concentrations following treatment with iron and furosemide. However, in some neonates, blood acetaldehyde concentrations were markedly elevated several hours post-dose. We infer that ethanol in drugs may cause elevation of blood acetaldehyde, a metabolite that has the potential to harm neonates. Hence, acetaldehyde may be a bigger concern than ethanol in infants administered these medicines. In principle, babies with genotypes associated with reduced ethanol- or acetaldehydemetabolising capacity should be treated with ethanol-free drug preparations. Whilst our observations imply a 'minimal ethanol in medicines' policy may be the only way of preventing neonates being inadvertently exposed to acetaldehyde through administration of medicines, presently, the risk of harms from acetaldehyde will need to be balanced against the likelihood of benefits from the active ingredient.

Authors contributions HP and MT planned the study. HP provided overall supervision and wrote the first draft and the final manuscript and vouches for these data. MT is the chief investigator of the ESNEE consortium and contributed to the final manuscript. $\mathrm{MH}$ and $\mathrm{HP}$ collected the blood samples. $\mathrm{MH}$ collected all the patient-related data and contributed to the final manuscript. RC and PSM developed and performed the bioanalytical assays for ethanol and acetaldehyde, contributed to the planning of the study and to the final manuscript. HM and HP performed data analysis. HM also contributed to the final manuscript. SY, AJN and JM contributed to the planning of the study and to the final manuscript.

\section{Compliance with ethical standards}

Funding source The ESNEE project has been funded through the European Research Area-Network PRIOMEDCHILD programme. In the UK, this was funded by the Medical Research Council, UK, in Estonia by the Estonian Science Foundation and in France by the Agence Nationale de la Recherche

Conflict of interest The authors declare that they have no conflicts of interest.

Ethical approval All procedures performed in the studies involving human participants were in accordance with the ethical standards of the institutional and/or national research committee and with the 1964 Helsinki declaration and its later amendments or comparable ethical standards. Informed consent was obtained from all individual participants included in the study. The study received ethical approval from NRES Committee North West - Greater Manchester North Rec, ref no: 11/NW/ 0665

Funding source The ESNEE project has been funded through the European Research Area-Network PRIOMEDCHILD programme. In the UK, this was funded by the Medical Research Council, UK, in Estonia by the Estonian Science Foundation and in France by the Agence Nationale de la Recherche

Clinical trial registration ISRCTN 31837223 
Open Access This article is distributed under the terms of the Creative Commons Attribution 4.0 International License (http:// creativecommons.org/licenses/by/4.0/), which permits unrestricted use, distribution, and reproduction in any medium, provided you give appropriate credit to the original author(s) and the source, provide a link to the Creative Commons license, and indicate if changes were made.

\section{References}

1. Bae KY, Kim SW, Shin HY et al (2012) The acute effects of ethanol and acetaldehyde on physiological responses after ethanol ingestion in young healthy men with different ALDH2 genotypes. Clin Toxicol (Phila) 50(4):242-249

2. Bosco C, Diaz E (2012) Placental hypoxia and foetal development versus alcohol exposure in pregnancy. Alcohol Alcohol 47(2):109117

3. Cohen-Wolkowiez M, Ouellet D, Smith PB et al (2012) Population pharmacokinetics of metronidazole evaluated using scavenged samples from preterm infants. Antimicrob Agents Chemother 56(4):1828-1837

4. Cohen-Wolkowiez M, Benjamin DK Jr, Ross A et al (2012) Population pharmacokinetics of piperacillin using scavenged samples from preterm infants. Ther Drug Monit 34(3):312-319

5. Cordell RL, Pandya H, Hubbard M, Turner MA, Monks PS (2013) GC-MS analysis of ethanol and other volatile compounds in microvolume blood samples-quantifying neonatal exposure. Anal Bioanal Chem 405(12):4139-4147

6. Kim SW, Bae KY, Shin HY et al (2010) The role of acetaldehyde in human psychomotor function: a double- blind placebo-controlled crossover study. Biol Psychiatry 67(9):840-845

7. Kristensen HG (2012) WHO guideline development of paediatric medicines: points to consider in pharmaceutical development. Int $\mathrm{J}$ Pharm 435(2):134-135

8. Laughon MM, Benjamin DK Jr, Capparelli EV et al (2011) Innovative clinical trial design for pediatric therapeutics. Expert Rev Clin Pharmacol 4(5):643-652

9. Logan BK, Jones AW (2000) Endogenous ethanol 'auto-brewery syndrome' as a drunk-driving defence challenge. Med Sci Law 40(3):206-215
10. Mills RJ, Davies MW (2012) Enteral iron supplementation in preterm and low birth weight infants. Cochrane Database Syst Rev 3: CD005095

11. Moore T, Hennessy EM, Myles J et al (2012) Neurological and developmental outcome in extremely preterm children born in England in 1995 and 2006: the EPICure studies. BMJ 345:e7961

12. Nahata MC (2009) Safety of "inert" additives or excipients in paediatric medicines. Arch Dis Child Fetal Neonatal Ed 94(6):F392393

13. Nunn T, Williams J (2005) Formulation of medicines for children. Br J Clin Pharmacol 59:674-676

14. Ostrovsky YM, Pronko PS, Shishkin SN, Kolesnikov VB, Volynets SI (1989) An attempt to evaluate diagnostic and prognostic significance of blood endogenous ethanol in alcoholics and their relatives. Alcohol 6:97-102

15. Owoeye OA (2014) Compulsory patent licensing and local drug manufacturing capacity in Africa. Bull World Health Organ 92(3): 214-219

16. Rayar P, Ratnapalan S (2013) Pediatric ingestions of house-hold products containing ethanol: a review. Clin Pediatr (Phila) 52(3): 203-209

17. Richardson H (1971) Furosemide in heart failure of infancy. Arch Dis Child 46(248):520-524

18. Sprung R, Bonte W, Rudell E, Domke M, Frauenrath C (1981) Zum Problem des endogenen. Alkohols Blutalhohol 18:65-70

19. Stewart A, Brion LP, Ambrosio-Perez I (2011) Diuretics acting on the distal renal tubule for preterm infants with (or developing) chronic lung disease. Cochrane Database Syst Rev 7(9):CD001817

20. Swarbrick J, Boylan JC (2002) Excipients. In: Encyclopedia of pharmaceutical technology. 2nd edn. New York: Marcel Dekker Inc 3:1132-1164

21. Wernovsky G, Shillingford AJ, Gaynor JW (2005) Central nervous system outcomes in children with complex congenital heart disease. Curr Opin Cardiol 20(2):94-99

22. Whittaker A, Currie AE, Turner MA, Field DJ, Mulla H, Pandya HC (2009) Toxic additives in medication for preterm infants. Arch Dis Child Fetal Neonatal Ed 94(4):F236-240

23. WHO Model List of Essential Medicines for Children 5th list (April 2015); http://www.who.int/entity/medicines/publications/ essentialmedicines/EMLc_2015_FINAL_amended AUG2015. pdf?ua $=1$ Accessed 6/02/2016

24. Zakhari S (2006) Overview: How is alcohol metabolized by the body? Alcohol Res Health 29(4):245-254 